\title{
Heritability and Components of Phenotypic Expression in Skin Reflectance of Mestizos From the Peruvian Lowlands
}

\author{
A. ROBERTO FRISANCHO, ROBERT WAINWRIGHT, AND ANTONY WAY \\ Center for Human Growth and Development and Department of Anthropology, \\ University of Michigan, Ann Arbor, Michigan 48109 (A.R.F.) (R.W.), and Department \\ of Preventive Medicine and Community Health, Texas Tech University School of \\ Medicine, Lubbock, Texas 79430 (A.W.)
}

\section{KEY WORDS Skin color, Heritability, Mestizos, Peru}

\begin{abstract}
Skin reflectance was measured on the inner upper arm and forehead of a sample of 209 Mestizos ranging in age from 2 to 64 years living in the town of Lamas in the Eastern Peruvian Lowlands. The sample consisted of 43 father-son, 42 father-daughter, 62 mother-son, and 70 mother-daughter pairs. The sample also consisted of 57 brother-brother, 60 sister-sister and 139 brothersister pairs. The reflectance measurements were made with a Photovolt Reflection Meter, model 670. Stepwise polynomial regression techniques were used to derive standardized residual values. Then using these residual values parent-offspring, sibling intraclass correlations and components of the phenotypic expression of skin reflectance were calculated. The study indicates that 1) the parent-offspring and sibling correlation coefficients conformed with the theoretical correlations expected assuming polygenic inheritance; 2 ) the husband-wife correlations indicate a high degree of assortative mating for skin color, but despite this effect the parent-offspring and sibling correlation coefficients are lower than the values expected under the influence of autosomal genes; 3 ) estimates of heritability and components of phenotypic expression indicate that about 55\% of the total variability in skin reflectance could be attributed to the influence of additive genetic factors; and 4) there is no evidence of X-linkage in the inheritance of skin color.
\end{abstract}

The main approach for studying the inheritance of quantitative traits is the study of resemblance between relatives. The degree of resemblance between relatives in metric traits is measured by the heritability $\left(h^{2}\right)$. The heritability of a character expresses the proportion of the total phenotypic variance $\left(V_{p}\right)$ that is attributable to the additive (average) effect of genes $\left(V_{A}\right)$; that is $h^{2}=V_{A} / V_{p}$. Estimates of heritability are based on the assumption that the total phenotypic variance of trait $\left(V_{p}\right)$ is equal to the sum of genetic additive variance $\left(V_{A}\right)$, common environmental variance $\left(V_{E_{c}}\right)$, and within family environmental variance $\left(V_{E w}\right)$. Human biologists have used this approach to estimate the genetic and environ- mental components of anthropometric traits but little attention has been given to skin color.

Skin reflectance measurements have been used to ascertain the degree of racial admixture among native and nonnative Mexican populations (Lasker, 1954), African blacks, and European whites (Barnicot, 1958; Harrison and Owen, 1964; Harrison et al., 1967). However, because of the lack of family data, the degree of heritability and the components of phenotypic expression in skin color have not been defined yet. For this reason, in this study of a Mestizo population living in the Peruvian

Received March 25, 1980; accepted November 16, 1980. 
Eastern Lowlands, we have analyzed the heritability and components of phenotypic expression of skin reflectance measurements.

\section{METHODS AND MATERIALS}

\section{Sample}

The subject population was drawn from the town of Lamas in the Department of San Martin, Peru. The 1961 Peruvian census indicates that the population of the district of Lamas was 12,866 , of whom 7,139 inhabitants were located in the central town of Lamas and 5,727 people were distributed among the aggregated native-owned settlements. The town of Lamas is $1,320 \mathrm{~m}$ above sea level, making it one of the highest populated locations in the Province of Lamas. The climate is that of moderate heat stress, the average annual temperature being about $27^{\circ} \mathrm{C}$ with a relative humidity of about $50 \%$.

The population of the town consists of two distinct and separate ethnic groups: the indigenous Quechua and the Mestizos. The Mestizos are descendants of Spanish-speaking inhabitants who settled in the region during the colonial period and founded the town of Lamas in 1650. Mestizos from the Peruvian coast and highlands have also contributed to the population of the town. This Mestizo population is of a variable Spanish and indigenous admixture.

The sample consisted of 209 Mestizo subjects ranging in age from 2 to 64 years, of whom 94 were males and 115 were females. The sample included 65 parents with a total of 144 offspring. From this sample a number of parentoffspring and sibling pairs were formed. The parent-offspring sample consisted of 43 fatherson, 42 father-daughter, 85 father-offspring, 62 mother-son, 70 mother-daughter, and 132 mother-offspring pairs. The sibling sample consisted of 57 brother-brother, 60 sister-sister, and 139 brother-sister pairs. The ages of all subjects were derived from birth records provided by the school official of Lamas or the parents themselves.

\section{Measurements}

The skin reflectance readings used in this study were obtained with a Photovolt Reflection Meter, model 670. Reflectance readings were obtained from five filters identified as red, triamber, trigreen, triblue, and blue. These filters have transmission peaks of approximately $670 \mathrm{~nm}$ (red), $600 \mathrm{~nm}$ (triamber), 550 $\mathrm{nm}$ (trigreen), $450 \mathrm{~nm}$ (triblue), and $420 \mathrm{~nm}$ (blue) (Hunter, 1942; Conway and Baker, 1972). Two sites were measured on each subject: 1) the inner upper arm distal to the axillary region of the arm; and 2) the forehead, directly on the glabella. On each subject at least two readings were averaged for each site with each filter. About 15 minutes prior to the measurements all subjects were thoroughly cleaned with cotton and alcohol on the two sites. The study was conducted during the month of July 1974. Intercorrelations among all the five filters ranged from 0.85 to 0.95 for the upper inner arm and from 0.79 to 0.92 for the forehead. Furthermore, the correlation coefficients between the first and second readings in all five filters exceeded 0.95 . These data indicate a good degree of reliability and replicability in the measurements of skin reflectance.

\section{Analysis}

Parent-Offspring and Sibling Correlations. As shown in Table 1, the skin reflectance measurements indicate a rapid darkening from infancy to beginning teens, followed by a lightening trend through adulthood. In view of these changes in skin reflectance readings, it was necessary to obtain a value that is not affected by age and permit direct estimates of parent-offspring and sibling relationships. For this purpose stepwise polynomial regressions of reflectance readings on age were calculated for each sex. From these polynomial regressions we chose the regressions that gave the best fit to the data. Then, based on these polynomial regressions the skin reflectance readings were predicted for each sex and each individual value was expressed in terms of its distance from the predicted regression line. These residual values, rather than the raw reflectance readings, were used to determine the correlation coefficients between parents and offspring and sibling pairs. As shown in Table 1 the skin reflectance measurements at the forehead in males and females are significantly lower than the skin reflectance at the upper inner arm. These differences are related to the fact that the effects of exposure to solar radiation at the forehead are greater than on the inner upper arm. For these reasons, the analysis of heritability of skin color is based only upon measurements of skin reflectance at the upper inner arm.

Heritability. As indicators of heritability $\left(h^{2}\right)$ midparent-offspring regression coefficients were calculated using the residual val- 
TABLE 1. Mean and standard deviations of percent skin reflectance measurements of mestizo samples living in the Eastern Peruvian Lowlands

\begin{tabular}{|c|c|c|c|c|c|c|c|c|c|c|c|c|}
\hline \multirow{3}{*}{$\begin{array}{c}\text { Age group } \\
\text { (years) }\end{array}$} & \multicolumn{2}{|c|}{ Mean } & \multicolumn{10}{|c|}{ Inner arm } \\
\hline & \multirow{2}{*}{ age } & \multirow{2}{*}{$\mathbf{N}$} & \multicolumn{2}{|c|}{ Red } & \multicolumn{2}{|c|}{ Triamber } & \multicolumn{2}{|c|}{ Trigreen } & \multicolumn{2}{|c|}{ Triblue } & \multicolumn{2}{|c|}{ Blue } \\
\hline & & & Mean & S.D. & Mean & S.D. & Mea & S.D. & Mean & S.D. & Mean & S.D. \\
\hline \multicolumn{13}{|l|}{ Males } \\
\hline $2-4.9$ & 4.0 & 2 & 57.0 & 1.4 & 42.2 & 4.8 & 35.5 & 4.9 & 22.5 & 2.1 & 29.5 & 4.9 \\
\hline $5-7.9$ & 6.2 & 18 & 51.4 & 3.3 & 33.6 & 3.9 & 27.3 & 3.9 & 15.7 & 3.0 & 22.4 & 3.2 \\
\hline $8-10.9$ & 8.7 & 18 & 49.8 & 2.7 & 31.9 & 3.2 & 25.2 & 2.9 & 14.0 & 2.4 & 20.7 & 2.8 \\
\hline $11-13.9$ & 11.7 & 18 & 48.7 & 3.5 & 29.9 & 6.8 & 24.1 & 3.3 & 14.2 & 4.3 & 19.7 & 3.2 \\
\hline $14-16.9$ & 14.8 & 10 & 48.6 & 3.9 & 30.6 & 4.8 & 24.1 & 3.8 & 13.5 & 3.2 & 19.2 & 3.4 \\
\hline $17-19.9$ & 17.5 & 4 & 51.8 & 3,8 & 34.3 & 5.1 & 27.0 & 4.7 & 16.2 & 4.4 & 23.0 & 5.4 \\
\hline $30-62.9$ & 43.3 & 24 & 54.0 & 4.1 & 36.8 & 5.5 & 29.5 & 5.4 & 18.8 & 5.5 & 24.8 & 5.5 \\
\hline \multicolumn{13}{|l|}{ Females } \\
\hline $2-4.9$ & 3.0 & 4 & 51.8 & 3.1 & 35.0 & 3.6 & 29.2 & 4.3 & 17.8 & 4.5 & 23.8 & 5.5 \\
\hline $5-7.9$ & 6.0 & 21 & 50.2 & 2.0 & 32.0 & 2.4 & 24.8 & 3.6 & 14.3 & 1.5 & 20.7 & 1.6 \\
\hline $8-10.9$ & 8.9 & 17 & 49.7 & 3.7 & 31.7 & 3.7 & 24.5 & 4.2 & 14.6 & 2.5 & 20.8 & 2.9 \\
\hline $11-13.9$ & 11.9 & 17 & 48.8 & 4.3 & 31.3 & 5.5 & 24.6 & 4.7 & 13.9 & 3.3 & 19.9 & 3.9 \\
\hline $14-16.9$ & 15.4 & 8 & 49.4 & 4.4 & 31.9 & 5.4 & 24.8 & 5.5 & 14.4 & 4.4 & 20.1 & 4.4 \\
\hline $17-19.9$ & 17.5 & 4 & 54.0 & 1.2 & 37.5 & 0.9 & 29.8 & 0.5 & 18.5 & 1.7 & 25.0 & 0.8 \\
\hline $24-58.9$ & 37.3 & 41 & 50.4 & 4.2 & 33.6 & 4.6 & 26.5 & 5.0 & 15.5 & 3.8 & 22.1 & 3.9 \\
\hline
\end{tabular}

ues for skin color. These midparent-offspring regression coefficients should be relatively uninfluenced by assortative mating (Falconer, 1967). In addition, using the parent-offspring correlations $\left(r_{\mathrm{po}}\right)$ and the correlation between husband and wife $\left(r_{\mathrm{HW}}\right)$, estimates of heritability expected under panmictic conditions $\left(\mathrm{ho}^{2}\right)$ were calculated according to the procedures of Fisher (1918) and applied by Susanne (1977):

$$
\begin{aligned}
\mathrm{ho}^{2} & =\frac{\mathrm{h}^{2}(1-\mathrm{Mg})}{1-\mathrm{h}^{2} \mathrm{Mg}} \\
\text { where } \mathrm{h}^{2} & =\frac{2 \mathrm{r}_{\mathrm{po}}}{1+\mathrm{M}_{\mathrm{p}}}
\end{aligned}
$$

where $M_{\mathrm{p}}=$ the correlation coefficient

between husband and wife $\left(\mathbf{r}_{\mathrm{HW}}\right)$, and

$$
\mathrm{Mg}=\mathrm{h}^{2} \times \mathrm{M}_{\mathrm{p}}
$$

The advantage of this method is that it removes the effect of assortative mating in skin color from the estimates of heritability.

Components of Phenotypic Variance. As part of the analyses of sibling relationships, intraclass sibling correlation coefficients were calculated. For this purpose, using the residual values, the variability in skin reflectance measurements were partitioned into four components: between fathers $\left(\sigma_{\mathrm{F}}{ }^{2}\right)$, between moth- ers $\left(\sigma_{M}{ }^{2}\right)$, between sons $\left(\sigma_{B}^{2}\right)$, and between daughters $\left(\sigma_{\mathrm{S}}{ }^{2}\right)$. These calculations were done taking into account the effect of unequal family sizes (Sokal and Rohlf, 1969). Then, with these variance components, the percent additive genetic variance $\left(\mathrm{V}_{\mathrm{A}}\right)$, common environmental variance $\left(V_{E C}\right)$, and within-family environmental variance $\left(\mathrm{V}_{\mathrm{EW}}\right)$ that contributed to the total phenotypic variance $\left(V_{p}\right)$ were calculated according to Falconer (1967).

$$
\begin{aligned}
\mathrm{V}_{\mathrm{p}}= & \mathrm{V}_{\mathrm{A}}+\mathrm{V}_{\mathrm{EC}}+\mathrm{V}_{\mathrm{EW}} \text { where } \mathrm{V}_{\mathrm{A}} \\
= & 4 \sigma^{2} \mathrm{~F} ; \mathrm{V}_{\mathrm{EC}} \\
= & \sigma^{2} \mathrm{~F}-\sigma^{2} \mathrm{M} ; \text { and } \mathrm{V}_{\mathrm{EW}} \\
= & \sigma^{2} \mathrm{~S}+\sigma^{2} \mathrm{~B}-2 \sigma^{2} \mathrm{~F} . \\
& \quad \text { RESULTS }
\end{aligned}
$$

\section{Correlation coefficients}

Table 2 gives the correlation coefficients between husband and wife, parent and offspring, and the intraclass sibling correlation coefficients in skin reflectance measurements. From these data the following are evident: 1) All correlation coefficients are significant at the 0.05 level or better; 2) the mother-daughter correlations are systematically higher than the mother-son and father-son correlations; 3 ) the sister-sister intracorrelations are systematically higher than the brother-brother and brother-sister correlations; 4) the sibling correlation coefficients are lower than the values 


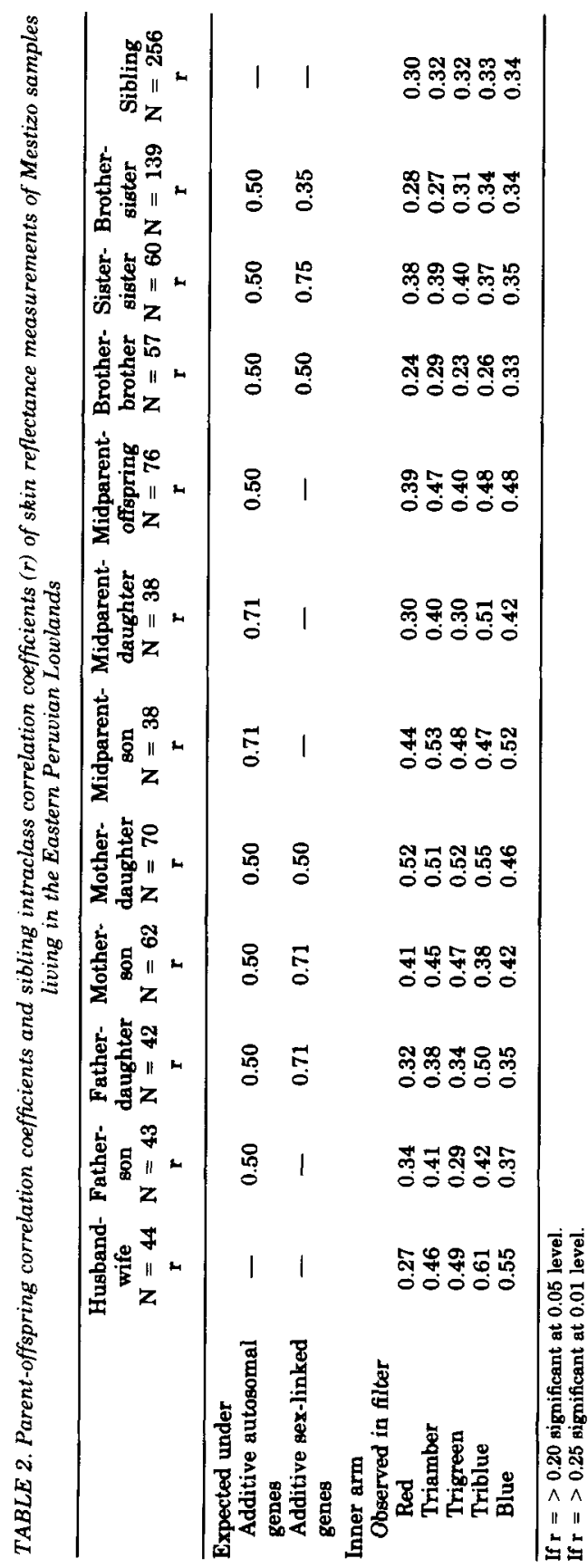

expected under additive autosomal genetic influence; 5) the mother-daughter and motherson correlation coefficients approach the values expected under additive autosomal genetic influence; 6 ) the mother-daughter correlations also approach the values expected under the effect of additive X-linked genes but the mother-son correlations are much lower than expected; 7) except for the father-daughter correlation for the blue filter, the parent-offspring correlations do not approach the values expected under additive autosomal or X-linked inheritance; 8) the parent-offspring correlations are greater than the sibling intraclass correlations.

\section{Heritability}

As shown in Tables 3 and 4, the estimates of heritability in skin reflectance derived from parent-offspring correlation coefficients adjusted for the effect of nonrandom assortative mating are similar to the heritability estimates derived from the midparent-offspring regression coefficients. As indicated by the midparent-offspring estimates heritability in skin reflectance ranges from $51 \%$ to $63 \%$. In other words, it appears that about $57 \%$ of the total variability in skin reflectance can be attributed to additive heritability.

Components of phenotypic expression

The components of phenotypic expression in skin reflectance at the inner upper arm are summarized in Table 5 and illustrated in Figure 1. From these results it is evident that additive genetic variance accounted for about $56 \%$ of the total phenotypic variability, common environment contributed about $2 \%$, and within-family environment the remaining $42 \%$.

TABLE 3. Percent heritability estimates $\left(\% h^{2}\right)$ derived from midparent-offspring correlation coefficients, adjusted for the effect of nonrandom assortative mating, in skin reflectance at the inner upper arm of Mestizo samples living in the Eastern Peruvian Lowlands

\begin{tabular}{lccc}
\hline & $\begin{array}{c}\text { Midparent- } \\
\text { son } \\
\text { \% } \\
\% \mathrm{~h}^{2}\end{array}$ & $\begin{array}{c}\text { Midparent- } \\
\text { daughter } \\
\mathbf{N}=38 \\
\%^{2}\end{array}$ & $\begin{array}{c}\text { Midparent- } \\
\text { offspring } \\
\mathbf{N}=76 \\
\%^{2} \mathbf{h}^{2}\end{array}$ \\
\hline Red & 64.7 & 43.8 & 57.0 \\
Triamber & 63.8 & 47.6 & 56.0 \\
Trigreen & 55.3 & 35.2 & 47.2 \\
Triblue & 47.5 & 51.5 & 48.4 \\
Blue & 56.2 & 45.3 & 51.8 \\
\hline
\end{tabular}


TABLE 4. Percent heritability estimates, $\% h^{2}$, derived from midparent-offspring regression coefficients in skin reflectance at the upper inner arms of Mestizo samples living in the Eastern Peruvian Lowlands

\begin{tabular}{|c|c|c|c|c|c|c|}
\hline & \multicolumn{2}{|c|}{$\begin{array}{l}\text { Midparent-son } \\
\qquad \mathbf{N}=\mathbf{3 8}\end{array}$} & \multicolumn{2}{|c|}{$\begin{array}{l}\text { Midparent-daughter } \\
\qquad \mathbf{N}=\mathbf{3 8}\end{array}$} & \multicolumn{2}{|c|}{$\begin{array}{l}\text { Midparent-offspring } \\
\qquad N=76\end{array}$} \\
\hline & $\mathbf{b} \pm \mathbf{S} . \mathbf{E}$ & $\% \mathrm{~h}^{2}$ & $\mathbf{b} \pm$ S.E. & $\% \mathrm{~h}^{2}$ & $\mathbf{b} \pm \mathbf{S} . \mathbf{E}$ & $\% \mathrm{~h}^{2}$ \\
\hline & $0.53 \pm 0.18^{* *}$ & $\mathbf{5 3 . 0}$ & $0.35 \pm 0.18$ & 35.0 & $0.47 \pm 0.13^{* *}$ & 47.0 \\
\hline Triamber & $0.76 \pm 0.23^{* *}$ & 86.0 & $0.39 \pm 0.15^{*}$ & 39 & $0.63 \pm 0.14^{* *}$ & 63.0 \\
\hline Trigreen & $0.49 \pm 0.15^{* *}$ & 49.0 & $0.31 \pm 0.17$ & 31.0 & $0.42 \pm 0.11^{* *}$ & 42.0 \\
\hline Triblue & $0.47 \pm 0.15^{* *}$ & 47.0 & $0.41 \pm 0.12^{* *}$ & 41.0 & $0.45 \pm 0.09^{* *}$ & 45.0 \\
\hline Blue & $0.51 \pm 0.14^{* *}$ & 51.0 & $0.40 \pm 0.14^{* *}$ & 40.0 & $0.47 \pm 0.09^{* *}$ & 47.0 \\
\hline
\end{tabular}

"P< 0.05; **P $<0.01$.

TABLE 5. Estimates of the percentage contribution of additive genetic variance $\left(V_{A}\right)$, common environmental variance $\left(V_{\mathrm{EC}}\right)$, and variance withinfamily environment $\left(V_{\mathrm{BW}}\right)$ to phenotypic variance $\left(V_{\mathrm{p}}\right)$ in skin reflectance of the inner upper arm of Mestizo samples living in the Eastern Peruvian Lowlands

\begin{tabular}{lccc}
\hline & \multicolumn{3}{c}{$\begin{array}{c}\text { Components of phenotypic } \\
\text { variance }\left(\mathrm{V}_{\mathrm{p}}\right)\end{array}$} \\
\cline { 2 - 4 } & $\mathrm{V}_{\mathrm{A}}(\%)$ & $\mathrm{V}_{\mathrm{EC}}(\%)$ & $\mathrm{V}_{\mathrm{EW}}(\%)$ \\
\hline Red & 58.7 & 1.3 & 40.0 \\
Triamber & 46.4 & 1.4 & 52.2 \\
Trigreen & 55.8 & 1.0 & 43.2 \\
Triblue & 59.2 & 2.4 & 38.4 \\
Blue & 63.9 & 2.3 & 33.8 \\
Weighted average & 56.1 & 1.6 & 42.3 \\
\hline
\end{tabular}

\section{DISCUSSION}

In general, both the parent-offspring correlations and the sibling intraclass correlations are of similar magnitude to those derived from metric characters. This finding supports the hypothesis that the pattern of heritabilities in skin color, like that of metric traits, is polygenic. However, the estimates of heritability and analyses of the components of phenotypic expression indicate that additive genetic factors accounted for about only $55 \%$ of the variability in skin reflectance. Furthermore, the parent-offspring and sibling correlation coefficients are lower than the values expected under the influence of additive autosomal genes. Therefore other forms of inheritance might account for the variability in skin color.

For example, if dominance and epistasis are involved in the expression of skin color, the parent-offspring correlations will be reduced

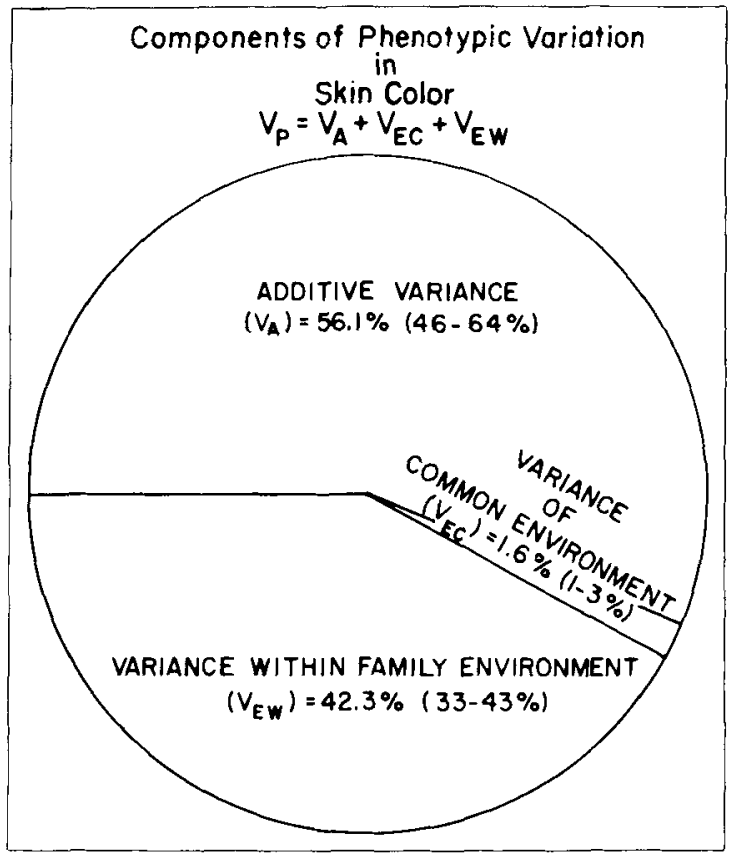

Fig. 1. Components of phenotypic expression in skin color of Peruvian Mestizos. Note that of the total phenotypic variance $\left(V_{p}\right)$ in skin color $56 \%$ is due to the effect of additive genetic inheritance $\left(V_{A}\right), 42 \%$ is due to the variance within family environment $\left(\mathrm{V}_{\mathrm{EW}}\right)$, whereas $2 \%$ is due to variance of common environment $\left(V_{E C}\right)$.

and hence the heritability would be underestimated. In theory in the absence of dominance the parent-offspring correlations is expected to be less than that of the sibling correlations. However, in the present study, the reverse is found; the parent-offspring correlations are higher than the sibling correlation. Another way of testing the influence of dominance factors is to evaluate the regression of offspring values on parental values. For this reason, we have calculated multiple regression coefficients between the skin reflectances of the 
TABLE 6. Multiple regression equations of father $\left(x_{1}\right)$ and mother $\left(x_{2}\right)$ on offspring $(y)$ skin reflectance readings at the upper inner arm for test of dominance among Mestizo samples from lamas

$y=a+b_{1} x_{1}+b_{2} x_{2}+b_{3} x_{1} x_{2}, N=76$

\begin{tabular}{ll}
\hline Red & $\mathrm{y}=0.89+0.39 \mathrm{x}_{1}+0.34 \mathrm{x}_{2}-0.10 \mathrm{x}_{1} \mathrm{x}_{2}$ \\
Triamber & $\mathrm{y}=0.52+0.38 \mathrm{x}_{1}+0.37 \mathrm{x}_{2}-0.05 \mathrm{x}_{1} \mathrm{x}_{2}$ \\
Trigreen & $\mathrm{y}=0.97+0.28 \mathrm{x}_{1}+0.29 \mathrm{x}_{2}-0.06 \mathrm{x}_{1} \mathrm{x}_{2}$ \\
Triblue & $\mathrm{y}=0.96+0.30 \mathrm{x}_{1}+0.18 \mathrm{x}_{2}-0.04 \mathrm{x}_{1} \mathrm{x}_{2}$ \\
Blue & $\mathrm{y}=0.76+0.21 \mathrm{x}_{1}+0.30 \mathrm{x}_{2}-0.02 \mathrm{x}_{1} \mathrm{x}_{2}$
\end{tabular}

father, mother, and offspring according to Fisher and Gray's method (1937):

$\mathbf{y}=a+b_{1} x_{1}+b_{2} x_{2}+b_{3} x_{1} x_{2}$,

where $y=$ the offspring's skin reflectance,

$\mathrm{a}=$ the $\mathrm{y}$-intercept; $\mathrm{x}_{1}=$ the father's skin reflectance;

$\mathbf{x}_{2}=$ the mother's skin reflectance; $b_{1}=$ the regression coefficient of the father; $b_{2}=$ the regression coefficient of the mother; $b_{3}=$ the regression coefficient for the product of the father's and mother's skin reflectance.

In this case $b_{3}$ represents the nonadditive factor of the parental influences. A positive $b_{3}$ term implies a negative bias in dominance where the heterozygote more nearly resembles the smaller than the larger homozygote. A negative $b_{3}$ term corresponds to a positive influence of dominance. As shown in Table 6, the $b_{3}$ coefficient for all five filters is negative, suggesting that dominance in skin reflectance plays a minimal role. These findings support the inference that if dominance operates in the expression of skin color it must be evenly balanced (Harrison and Owen, 1964). However, it is quite possible that dominance is involved in the expression of alleles at one or more loci, so that polygenic heterozygotes can have a greater expression of skin color than the parental polygenic homozygotes. Further investigations of large samples are required to clarify the role of dominance in polygenic inheritance. To clarify this point there is a need to evaluate the skin reflectance of offspring with respect to parental types of skin color. For example, comparing the skin reflectance of offspring where one of the parents is dark and the other is light can indicate the direction of dominance. Unfortunately, the small number of parents included in the present study does not allow for an adequate analysis of the results of different parental crosses.

In theory, as pointed out by Mather and Jinks (1963), when a given trait is under the influence of X-linked additive genes, the mother-son (or father-daughter) correlations are expected to be greater than the motherdaughter and father-son correlations. Similarly, the sister-sister correlations are expected to be higher than the brother-brother, which in turn are expected to be higher than the brother-sister correlations. The data in the present study demonstrate that the father-son correlations are similar to the father-daughter correlations and the brother-sister correlations are no less than the brother-brother correlations. These findings suggest that the expression of skin color is not under the influence of additive sex-linked genes.

\section{ACKNOWLEDGMENTS}

We thank the school children, directors, and teachers of the schools of the province of Lamas for their cooperation in this study. We also acknowledge assistance from Drs. Jane Klayman, Gary Borkan, and William Babler, former graduate students of the Department of Anthropology of the University of Michigan, in the collection of the data. We also thank Pamela Flegel and Nancy Becker for their assistance in manuscript preparation. The investigation has been supported in part by grant GS-37524X of the National Science Foundation.

\section{LITERATURE CITED}

Barnicot, NA (1958) Reflectometry of the skin of southern Nigerians and in some mulattoes. Hum. Biol. 30:150-160. Conway, DL, and Baker, PT (1972) Skin reflectance of Quechua Indians: The effects of genetic admixture, sex and age. Am. J. Phys. Anthropol. 36:267-282.

Falconer, DS (1967) Introduction to Quantitative Genetics. New York: The Ronald Press Company.

Fisher, RA (1918) The correlation between relatives on the supposition of mendelian inheritance. Trans R Soc Edin $52: 399-433$.

Fisher, RA, and Gray, H (1937) Inheritance in man: Boas' data studied by the method of analysis of variance. Ann. Hum. Genet. 8:74-93.

Harrison, GA, and Owen, JJT (1964) Studies on the inheritance of human skin colour. Ann. Hum. Genet. 28:27-37.

Harrison, GA, Owen, JJT, Rocha, FJD, and Salzano, FM (1967) Skin colour in southern Brazilian populations. Hum. Biol. 39:21-31.

Hunter, RS (1942) Photoelectric tristimulus colorimetry with three filters. Circular of the National Bureau of Standards C429, Washington, D.C.

Lasker, GW (1954) Photoelectric measurement of skin color in a Mexican Mestizo population. Am. J. Phys. Anthropol. 12:115-121.

Mather, K, and Jinks, JL (1963) Correlations between relatives arising from sex-linked genes. Nature 198:314-315.

Sokal, RR, and Rohlf, FJ (1969) Biometry. San Francisco: W. H. Freeman and Co., pp. 274-279.

Susanne, C (1977) Heritability of anthropological characters. Hum. Biol. 49:573-580. 